\title{
The Use of GIS, Remote Sensing and Shannon's Entropy Statistical Techniques to Analyze and Monitor the Spatial and Temporal Patterns of Urbanization and Sprawl in Zarqa City, Jordan
}

\author{
Atef F. Al Mashagbah \\ Department of GIS and remote sensing, Institute of Earth and Environmental Science, Al al-Bayt University, \\ Mafraq, Jordan \\ Email: atef.mashagbah@yahoo.com
}

Received 2 February 2016; accepted 25 April 2016; published 29 April 2016

Copyright () 2016 by author and Scientific Research Publishing Inc. This work is licensed under the Creative Commons Attribution International License (CC BY). http://creativecommons.org/licenses/by/4.0/

(c) (i) Open Access

\begin{abstract}
The aim of this study is to understand and quantify the urban growth and trend in Zarqa city during the period 1990 to 2014 and to produce land use and cover map for the studied area through the use of the GIS and remote sensing techniques with Shannon's Entropy statistical method. For this purpose, three Landsat images were used for land use classification by using supervised maximum likelihood classification techniques to extract and assess the changes of urban lands. The results indicated that the urban areas in Zarqa city increased by $22.15 \%$ in the period from 1990 to 2005 and $14.86 \%$ from 2005 to 2014, with a rate of expansion of 0.96 and by $1.31 \mathrm{~km}^{2} /$ year for the two time periods respectively. The entropy value increased from 1.20 in the first period to 1.38 in the second, while the entropy value for the NE, NW, SE and SW zones showed high values, which confirmed that urban expansion and sprawling had existed in the past twenty four years in the study area. Urban expansion and sprawl cause different impacts on the natural, economic, and aesthetic aspects of the city which lead and guide government officials and planners to understand and monitor current growth and visualize future growth.
\end{abstract}

\section{Keywords}

Landsat, Shannon Entropy, GIS, Remote Sensing, Urban Expansion, Urban Sprawl, Land Use/Cover, Zarqa, Jordan 


\section{Introduction}

Urban expansion and sprawling have become significant concern throughout the world in the past few decades [1]-[4]. They have economic, cultural and natural impacts; they increase cost of infrastructure, cause loss in farm and forest lands, increase consumption of energy and other environmental resources, raise land prices, cause crowding roads and heavy traffic, and decrease social interaction between people and other negative environmental impacts. The population growth and the construction of new roads, buildings, and other human made infrastructures and features impose on the city development authority and city planners to understand the current growth and to have up to date information and maps for future planning [5] [6].

Entropy is an efficient technique for comparing urban sprawl patterns [2] [7] [8], therefore, the Shannon's entropy for each zones and time period must be calculated, and the degree of sprawl can be measured by the value of entropy which varies from 0 to logarithm of number of zones or time period. The more compact of the structures and the built up areas is closer to zero entropy value, while the closer to the logarithm number of zones is the more dispersed the region [7] [9].

The image processing and classification in geographical information system and the remote sensing combined with statistical methods like Shannon entropy can be used to analyze, and detect Urban expansion and sprawling [10] [11]. The Zarqa District has experienced fast urbanization in the last few decades characterized by a spread of built up areas, for this reason, this study will use these methods and techniques to calculate and analyze the urban sprawl and urban growth pattern in Zarqa city within the last 24 years.

\section{Description of the Study Area}

Zarqa District is the third largest governorate in Jordan by population. It is located $25 \mathrm{~km}$ to northeast of the Jordanian capital Amman (Figure 1). Zarqa city is the capital of Zarqa Governorate. It is the industrial capital of Jordan, with many factories and Jordan's major oil refinery. Also, it functions as a large military center, with several military camps. It extends between latitudes $31^{\circ} 58^{\prime} \mathrm{N}$ and $32^{\circ} 06^{\prime} \mathrm{N}$ and longitudes $36^{\circ} 01^{\prime} \mathrm{E}$ and $36^{\circ} 20^{\prime} \mathrm{E}$, covering an area of $253.31 \mathrm{~km}^{2}$ with altitudes ranging between 508 to 803 meters above sea level.

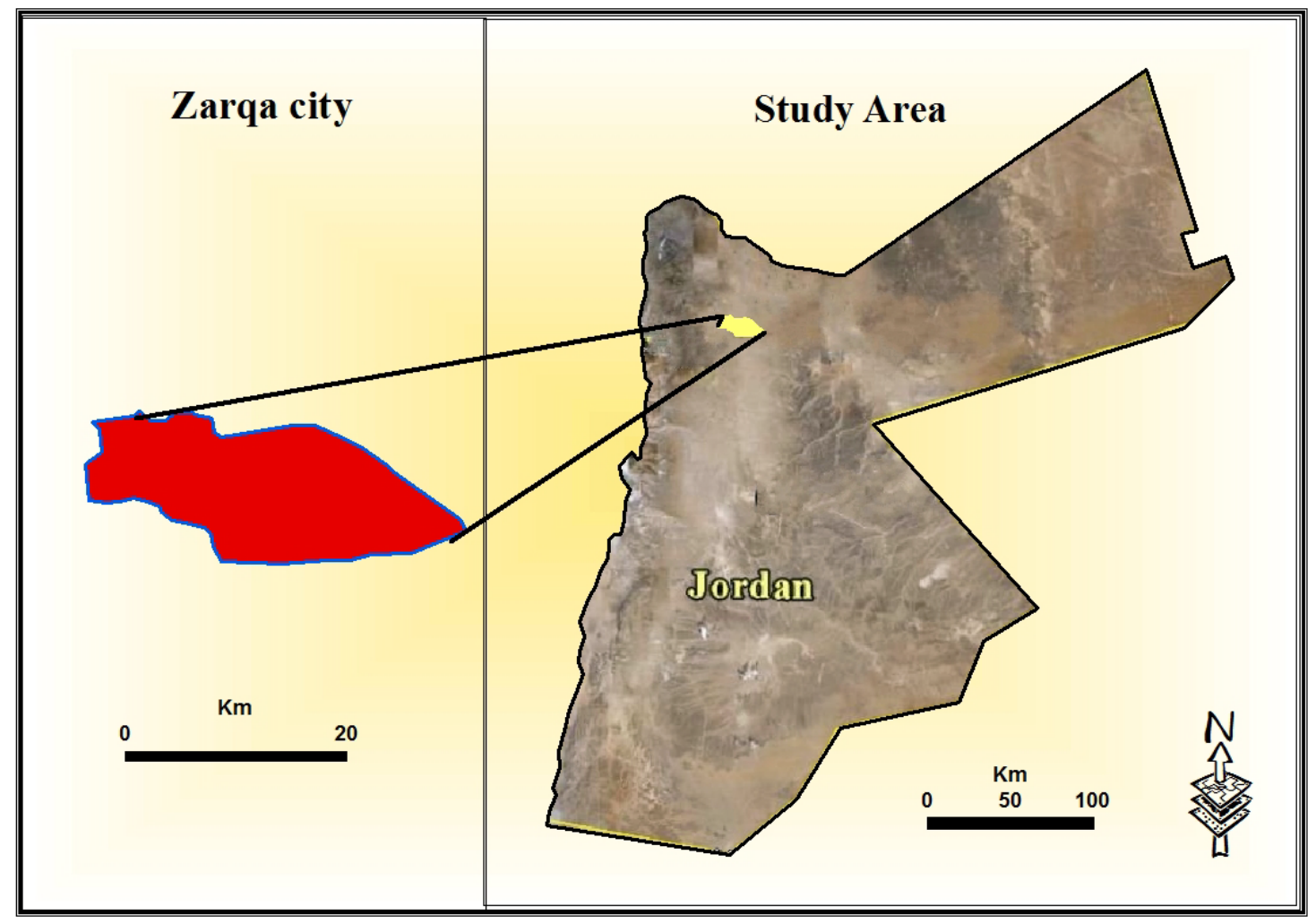

Figure 1. Location Map of the study area. 


\section{Methodology and Data Used}

Three Landsat images were used for land use classification. The satellite data covering the study area were obtained from earth explorer site (http://earthexplorer.usgs.gov) and global land cover facility site

(http://glcfapp.glcf.umd.edu.). The remotely sensed images Landsat-TM 1990; Landsat-ETM+ 2005 and Landsat-ETM+ 2014 were used in this study to derive the built-up area extents in Zarqa city using a supervised classification method.

The classification method started by clipping the satellite imageries using a vector map of the study area, afterwards, a supervised maximum likelihood classification technique in Arc map 10.2 was used to classify the clipped images to extract the urban areas.

The overall classification accuracy and the kappa coefficient of these classified imageries were $87.22 \%$ and 81.15\% in 1990, 85.84\% and 79.88\% in 2005 and $89.02 \%$ and $87.57 \%$ for 2014, respectively by comparing a selected real ground reference polygons with the classified output maps by computing Error Matrix.

In the study area only the built-up areas and barrens land found. For this reason, only two classes were considered, namely: urban class and non-urban class as shown in Figure 2.

Afterwards, classified imageries were clipped further into 4 zones namely NE, SE, SW and NW as shown in Figure 3. The built-up areas and urban growth for each zone were calculated using Shannon's entropy theory.

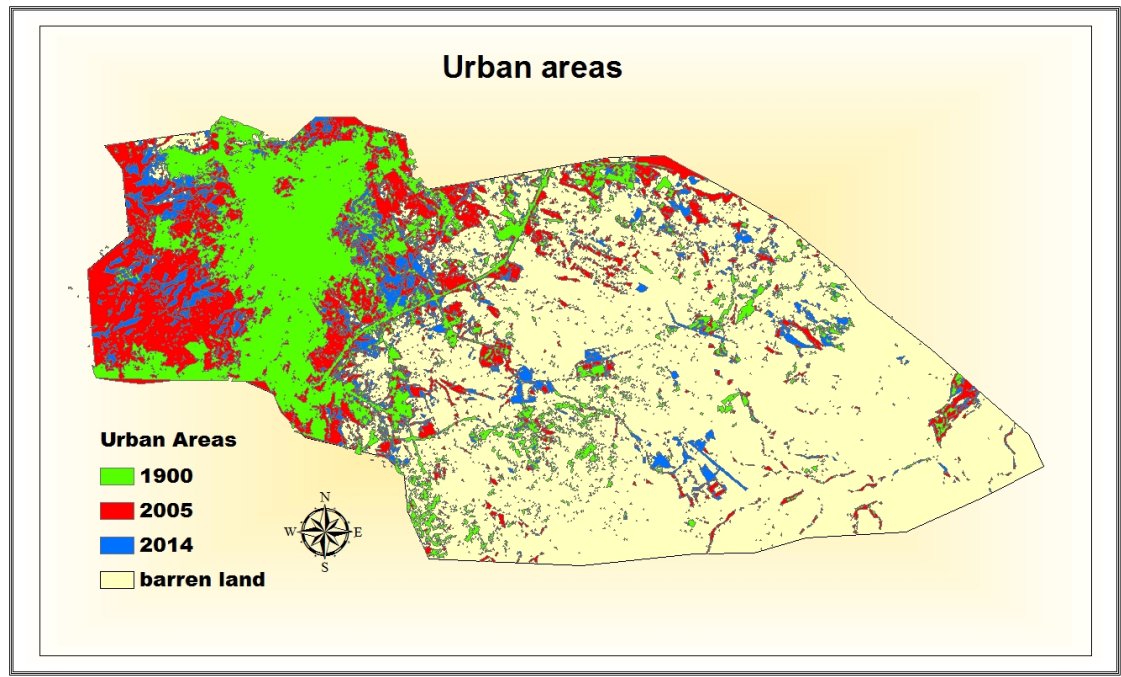

Figure 2. Urban and non-urban areas in 1990, 2005 and 2014.

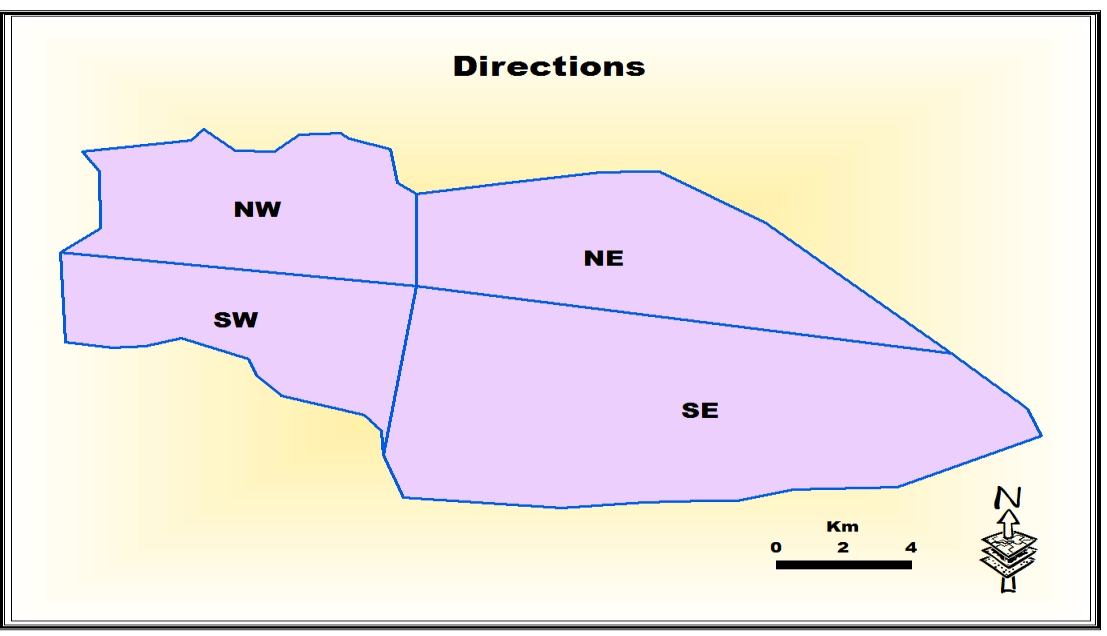

Figure 3. Zone map of the study site. 
Finally, the sprawl of Zarqa city was analyzed by dividing the study area into 4 zones, and then the percentage of built-up area for each zone was calculated by dividing the built-up area by the total area.

\section{Urban Sprawl and Shannon's Entropy}

Shannon's entropy method is used to determine whether the growth of urban areas was divergent or compact [2] [10].

The Shannon's entropy, Hn is given by Equation (1),

$$
\begin{aligned}
& H n=-\sum_{i=1}^{n} P i \log (P i) \\
& H n=-\sum_{i=1}^{n} P i \log (P i)
\end{aligned}
$$

where;

$P i=$ Proportion of the built-up areas in the ith zone.

$n=$ Total number of zones.

The value of the Shannon's Entropy is between 0 and $\log n .0$ means very dense urban areas whereas $\log n$ indicates urban sprawl areas [2].

\section{Results and Discussion}

The classified land use maps for the year 1990, 2005 and 2014 are shown in Figure 2. The urban and not urban areas were calculated from the classified maps and put into Table 1 and Table 2.

The trend and growth of urban sprawl was analyzed and the percent of urban land use categories for the two times period was computed (Table 2). As shown in Figure 4, the urban area in 1990 was $65 \mathrm{~km}^{2}$ and increased to $79.4 \mathrm{~km}^{2}$ in the year 2005 and 91.2 in 2014 with an increase of $14.4 \mathrm{~km}^{2}$ in the first period and 11.8 in the second period. The average annual growth rate was 1.48 and 0.99 percent respectively. During the period 19902005, the non-urban areas have a downward trend while there is an increase in urban areas with $22.2 \%$, while the period from 2005 to 2014 have another increase in urban areas of 14.9\% approximately.

The growth of built-up areas is mainly towards the southwest and northwest. The rest of the city still depicts dispersed built-up land patterns. The period 1990 to 2005 depicts a noticeable increase of 31.4\% in the built-up areas and the second time period has another increase $36.1 \%$. The increase of the urban area is a result of the increase in population and infrastructure developments in the city.

Four zones of the city were selected namely NE, SE, SW and NW which serves as growth zones of the city to evaluate whether the urban areas are growing equally. Table 3 shows the urban areas for each zone of each classified image while Table 4 shows the observed growth in urban area for 4 zones in the 2 time period and Table 5 shows the urban growth rate for each time period.

Table 4 indicates that in the period 1990-2014, the northeastern zone grew by $1 \mathrm{~km}^{2}$, the southeastern zone grew by $2.6 \mathrm{~km}^{2}$, the southwestern zone grew by $7.1 \mathrm{~km}^{2}$, while the northwestern zone grew by $15.5 \mathrm{~km}^{2}$ which has the maximum growth zone.

\begin{tabular}{|c|c|c|c|c|c|c|}
\hline \multirow{2}{*}{$\begin{array}{l}\text { Year } \\
\text { Area }\end{array}$} & \multicolumn{2}{|c|}{1990} & \multicolumn{2}{|c|}{2005} & \multicolumn{2}{|c|}{2014} \\
\hline & Area $\mathrm{km}^{2}$ & $\%$ & Area km² & $\%$ & Area km² & $\%$ \\
\hline Urban areas & 65 & 25.7 & 79.4 & 31.4 & 91.2 & 36.1 \\
\hline Non-urban areas & 187.6 & 74.3 & 173.6 & 68.6 & 161.6 & 63.9 \\
\hline
\end{tabular}

Table 1. Urban and non-urban areas $\left(\mathrm{km}^{2}\right)$ in 1990, 2005 and 2014.

Table 2. Percent change of urban and non-urban areas.

\begin{tabular}{ccc} 
Year & Year: 1990-2005 & Year: 2005-2014 \\
\hline Urban areas & 22.15 & 14.86 \\
Non-urban areas & -7.46 & -6.91 \\
\hline
\end{tabular}


As shown in Figure 5 and Figure 6 and Table 6, the rate of expansion for these zones for the 1990-2005 period is $0.01,0.10,0.25$ and $0.6 \mathrm{~km}^{2} /$ year respectively and $0.09,0.12,0.38$ and $0.72 \mathrm{~km}^{2} /$ year for the second period which indicate that the NW zone witnessed the largest growth and NE witnessed the smallest growth, meaning that the study area grew mainly in a westerly direction (Figure 7 and Figure 8).

Shannon's entropy was calculated for the urban area for each year and for each zone.

Shannon's entropy that reflects the built-up area is computed using Equation (1). Table 7 shows the entropy for the two time period. The entropy values for both periods are higher than the half of log (4), which indicates that the city is exhibiting more dispersion. The entropy value has increasing from 1.20 in the first period to 1.38 in the second indicating that the sprawling has extended.

The Entropy value for all zones showed high values. Table 8 shows the entropy values for each direction,

Table 3. Urban areas (in $\mathrm{km}^{2}$ ) in all zones from 1990 to 2014.

\begin{tabular}{cccccc}
\hline Year & NE & SE & SW & NW & Whole city \\
\hline 1990 & 7.1 & 6.3 & 20.3 & 31.3 & 65 \\
2005 & 7.3 & 7.8 & 24 & 40.3 & 79.4 \\
2014 & 8.1 & 8.9 & 27.4 & 46.8 & 91.2 \\
\hline
\end{tabular}

Table 4. Observed growth in urban area $\left(\mathrm{Km}^{2}\right)$.

\begin{tabular}{cccccc}
\hline Year & NE & SE & SW & NW & Total change \\
\hline Change 1990-2005 & 0.2 & 1.5 & 3.7 & 9 & 14.4 \\
Change 2005-2014 & 0.8 & 1.1 & 3.4 & 6.5 & 11.8 \\
Total & 1 & 2.6 & 7.1 & 15.5 & 26.2 \\
\hline
\end{tabular}

Table 5. Urban growth rate for the 2 time periods.

\begin{tabular}{ccccc}
\hline Rate of expansion & NE & SE & SW & NW \\
\hline $1990-2005$ & 0.028 & 0.238 & 0.182 & 0.288 \\
$2005-2014$ & 0.110 & 0.141 & 0.142 & 0.161 \\
\hline
\end{tabular}

Table 6. Uurban growth rate $\left(\mathrm{km}^{2} / \mathrm{year}\right)$ for the 2 time periods.

\begin{tabular}{ccccc}
\hline Rate of expansion $\left(\mathbf{k m}^{2} /\right.$ year $)$ & NE & SE & SW & NW \\
\hline $1990-2005$ & 0.01 & 0.10 & 0.25 & 0.60 \\
$2005-2014$ & 0.09 & 0.12 & 0.38 & 0.72 \\
\hline
\end{tabular}

Table 7. Shannon's entropy for the two time periods $(n=4)$.

\begin{tabular}{cccc}
\hline Time period & Entropy & $\log (\mathbf{n})$ & $\mathbf{1} / \mathbf{2} \log (\mathbf{4})$ \\
\hline $1990-2005$ & 1.20 & 1.39 & 0.693 \\
$2005-2014$ & 1.38 & 1.39 & \\
\hline
\end{tabular}

Table 8. Shannon's entropy for the different zones ( $n=$ sum of time period $=2$ ).

\begin{tabular}{ccccrrrr}
\hline Zone & NE & SE & SW & 0.69 & 0.65 \\
Entropy & 0.51 & 0.66 & 0.69 & 0.69 & 0.69 \\
\hline $\log (\mathrm{n})$ & 0.69 & 0.69 & \\
\hline
\end{tabular}


Built up area in 1990, 2005 and 2014 in $\left(\mathrm{km}^{2}\right)$.

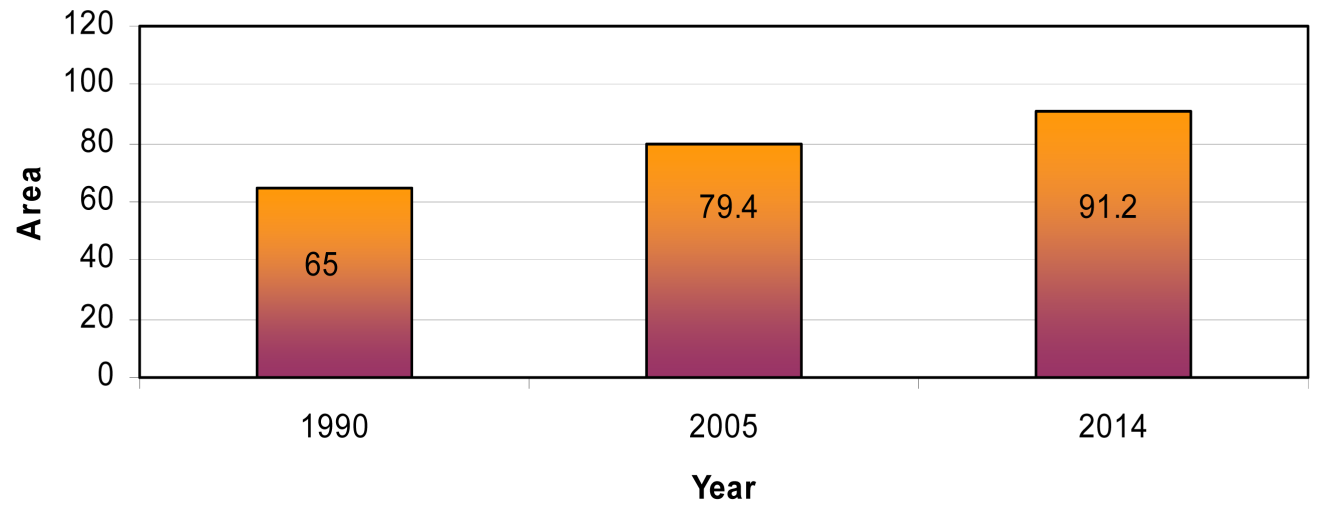

Figure 4. Overall urban areas in different years $\left(\mathrm{km}^{2}\right)$.

\section{Direction-wise rate of expansion during 1990-2005}

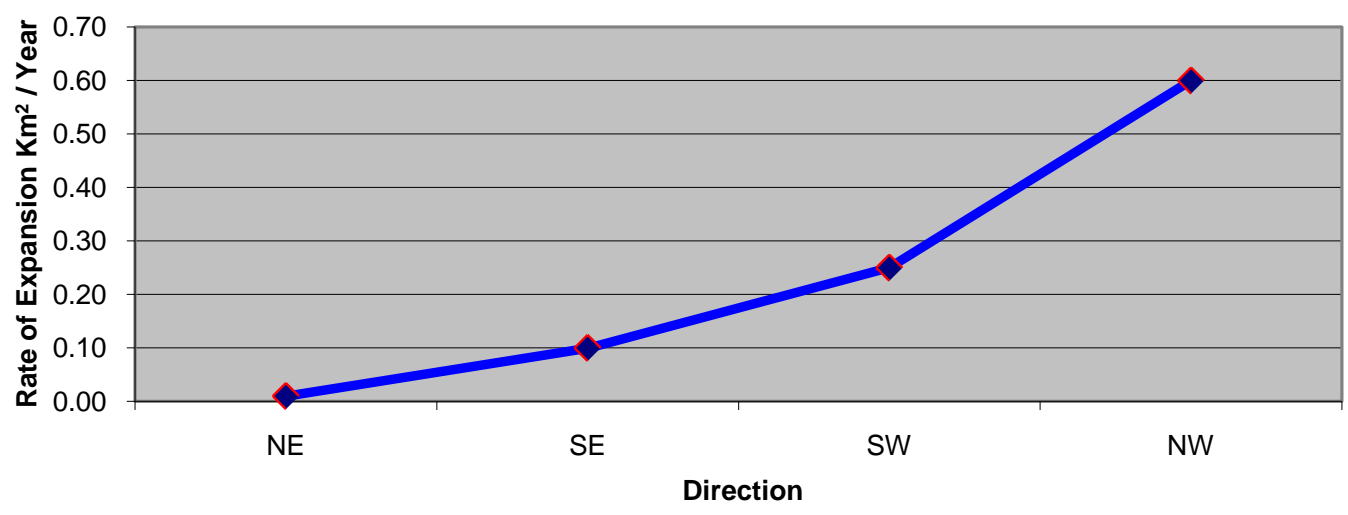

Figure 5. Rate of expansion of urban areas in the period 1990-2005.

\section{Direction-wise rate of expansion during 2005-2014}

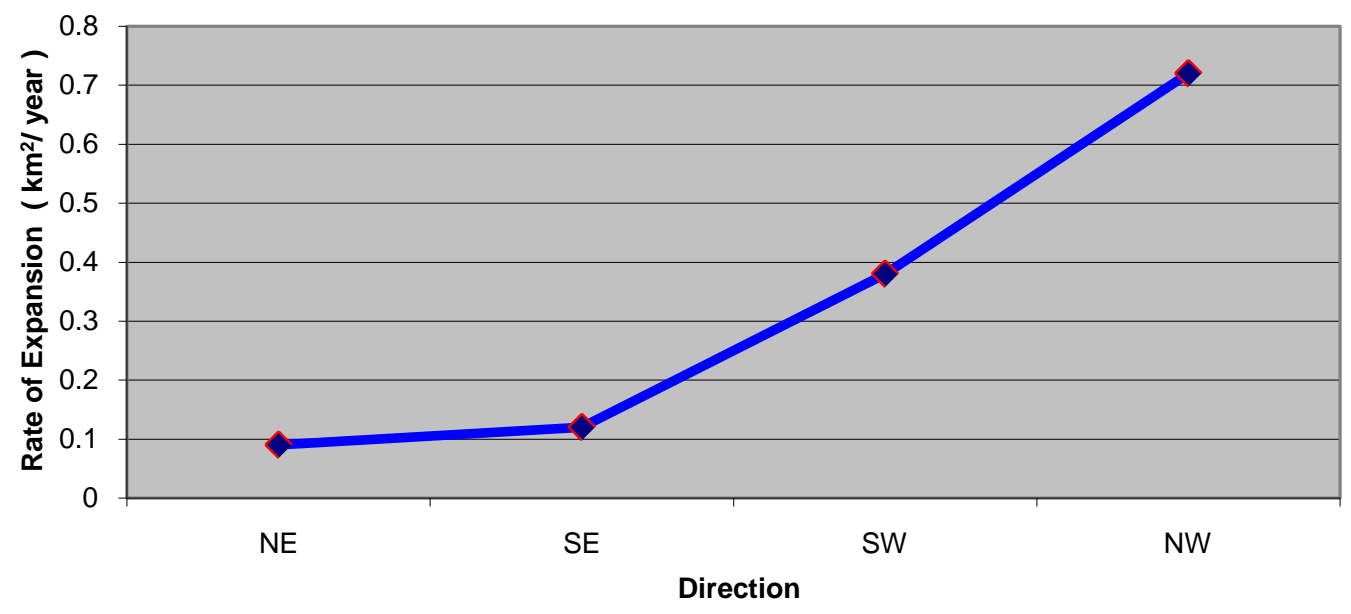

Figure 6. Rate of expansion of urban areas in the period 2005-2014. 


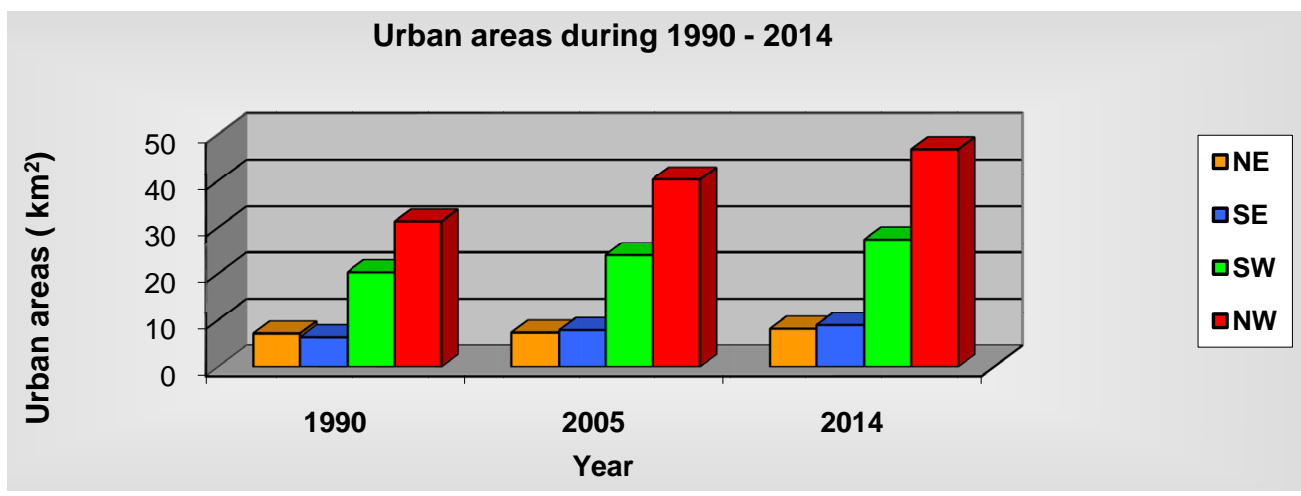

Figure 7. Urban areas during 1990-2014 (by year).

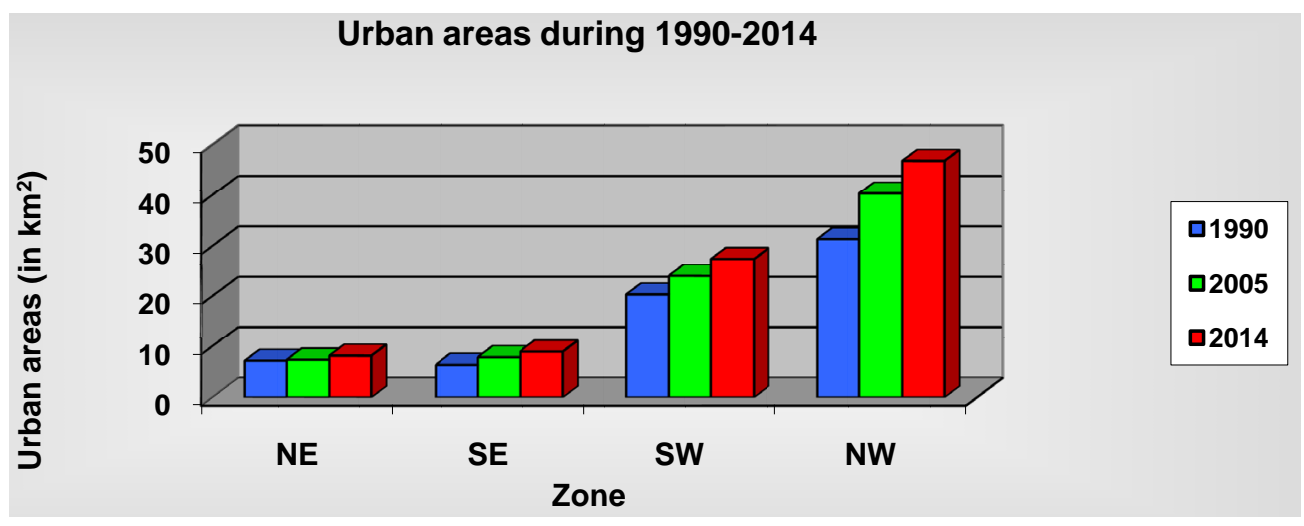

Figure 8. Urban areas during 1990-2014 (by direction).

which reveal that the entropy values are higher than 0.35 (the half of log e(2)), for the NE, NW, SE and SW zones which confirms that the sprawling has existed in the past twenty four years in the study area.

\section{Conclusion}

Urban growth change and trend in Zarqa city were computed and assessed by using three Landsat image during 1990 to 2014 by combining GIS, remote sensing and Shannon's Entropy statistical techniques in order to evaluate the urban growth and sprawl patterns and to produce land use and cover map for the studied area. The following conclusions were drawn on the basis of urban growth analysis of the study area.

\section{References}

[1] Mujtaba, S.M. (1994) Land Use and Environmental Change Due to Urban Sprawl: A Remote Sensing Approach. Daya Publishing House, New Delhi.

[2] Yeh, A.G.O. and Li, X. (2001) Measurement and Monitoring of Urban Sprawl in a Rapidly Growing Region Using Entropy. Photogrammetric Engineering and Remote Sensing, 67, 83-90.

[3] Muñiz, I. and Galindo, A. (2005) Urban Form and the Ecological Footprint of Commuting. The Case of Barcelona. Ecological Economics, 55, 499-514.

[4] Parka, S., Jeon, S., Kim, S. and Choi, C. (2011) Prediction and Comparison of Urban Growth by Land Suitability Index Mapping Using GIS and RS in South Korea. Landscape and Urban Planning, 99, 104-114. http://dx.doi.org/10.1016/j.landurbplan.2010.09.001

[5] Xu, H., Wang, X. and Xiao, G. (2000) A Remote Sensing and GIS Integrated Study on Urbanization with Its Impact on Arable Lands: Fuqing City, Fujian Province, China. Land Degradation \& Development, 11, 301-314. http://dx.doi.org/10.1002/1099-145X(200007/08)11:4<301::AID-LDR392>3.0.CO;2-N

[6] Al-Mashagbah, A., Al-Adamat, R. and Al-Amoush, H. (2012) GIS and Remote Sensing to Investigate Urban Growth in Mafraq City/Jordan between 1987 and 2010. Journal of Geographic Information System, 4, 377-382. 
http://dx.doi.org/10.4236/jgis.2012.44043

[7] Sudhira, H.S., Ramachandra, T.V. and Jagadish, K.S. (2004) Urban Sprawl: Metrics, Dynamics and Modeling Using GIS. International Journal of Applied Earth Observation and Geoinformation, 5, 29-39. http://dx.doi.org/10.1016/j.jag.2003.08.002

[8] Jat, M.K., Garg, P.K. and Khare, D. (2007) Monitoring and Modeling Urban Sprawl Using Remote Sensing and GIS Techniques. International Journal of Applied Earth Observation and Geoinformation, 10, 26-43. http://dx.doi.org/10.1016/j.jag.2007.04.002

[9] Sun, H., Forsythe, W. and Waters, N. (2007) Modeling Urban Land Use Change and Urban Sprawl: Calgary, Alberta, Canada. Network and Spatial Economics, 7, 353-376. http://dx.doi.org/10.1007/s11067-007-9030-y

[10] Li, X. and Yeh, A.G.O. (2004) Analyzing Spatial Restructuring of Land Use Patterns in A Fast Growing Region Remote Sensing and GIS. Landscape and Urban Planning, 69, 335-354. http://dx.doi.org/10.1016/j.landurbplan.2003.10.033

[11] Deka, J., Tripathi, O.P. and Khan, M. (2012) Urban Growth Trend Analysis Using Shannon Entropy Approach-A Case Study in North-East India. International Journal of Geomatics and Geosciences, 2, 1062-1068. 